\title{
Histological features of the nephrotic syndrome associated with quartan malaria
}

\author{
J. W. KIBUKAMUSOKE AND M. S. R. HUTT \\ From the Makerere University College Medical School and Mulago Hospital, Kampala, \\ Uganda, East Africa
}

SYNOPSIS The histological diagnosis in 77 cases of the nephrotic syndrome occurring in Uganda is presented. Plasmodium malariae was detected in 31 cases and all but one of these showed diffuse proliferative or focal glomerulonephritis. Pure membranous glomerulonephritis was seen in nine cases; none of these had parasitaemia. Children $(63 \%)$ had a higher incidence of parasitaemia than adults $(40 \%)$ in the cases examined.

The relationship between Plasmodium malariae infection and the nephrotic syndrome has now been established beyond doubt in several parts of the world (Clarke, 1912; Giglioli, 1930 and 1962a and b; McFie and Ingram, 1917; Gilles and Hendrickse, 1963; Kibukamusoke, 1966a, b, and c). However, the mechanism by which the renal lesion is produced is still obscure and there are few reports of the histological lesions in these cases either at necropsy or from renal biopsy studies (Giglioli, 1930; Menon and Annamalae, 1933; Allen, 1962; Gilles and Hendrickse, 1963).

The clinical features and malarial studies undertaken on cases of the nephrotic syndrome in Uganda have been published elsewhere (Kibukamusoke and Wilks, 1965a and b; Kibukamusoke, 1966b and c). We report here the histological findings in a series of 77 patients presenting with the nephrotic syndrome at the New Mulago Hospital, Kampala, between 1960 and 1965.

\section{MATERIALS AND METHODS}

RENAL BIOPSY This was performed by a modification of the technique described by Kark and Muehrcke (1954) using the adult prototype of White's (1962) modification of the Vim-Silverman needle (Kibukamusoke, 1966a).

After biopsy the renal tissue was immediately immersed in a solution of normal saline for five minutes in order to correct any distortion that might have been produced during the procedure. The biopsy was then transferred to a solution of $10 \%$ formal saline for fixation.

After paraffin embedding, sections were cut of 3 to $4 \mu$ thickness and stained with haematoxylin and eosin and by the periodic-acid-Schiff technique.

Received for publication 14 December 1966
Renal biopsy was performed in 77 of 80 cases. Success was gauged according to the amount of cortical tissue obtained in each individual biopsy. Adequate material was obtained in 68 cases during the first attempt in an initial success rate of $85 \%$. In the remainder, inadequate (cortical) tissue was obtained in six cases and in the remaining three cases no renal tissue was obtained. Adequate material, however, was obtained in all these nine cases at a second attempt. In three cases both attempts were unsuccessful and no histology is available on these. Two of these were adults and one of these a child of 10 .

In 26 cases renal tissue was obtained on one or two more occasions subsequently by biopsy ( 16 cases) or at necropsy (10 cases) either to confirm the original histological changes or to assess progress. In four cases, three or more such biopsies were performed over a period of one to two years.

In assessing glomerular changes, it was found useful to count the total number of nuclei in the glomerular tufts. Experience with a wide range of renal biopsies showed that counts of over 120 nuclei in a single glomerular tuft indicates a proliferative lesion.

RESULTS

The basic histological groups encountered in the 77 cases are shown in Table I.

PROLIFERATIVE GLOMERULONEPHRITIS The majority of cases fell into this group (55 patients). On histological grounds the biopsies were divided into five subgroups under the general heading of proliferative glomerulonephritis.

Diffuse The majority of glomeruli showed an increase in the number of nuclei in the glomerular tufts. In most of these biopsies the proliferation was 
TABLE I

HISTOLOGICAL DIAGNOSIS IN 77 CASES OF THE NEPHROTIC SYNDROME

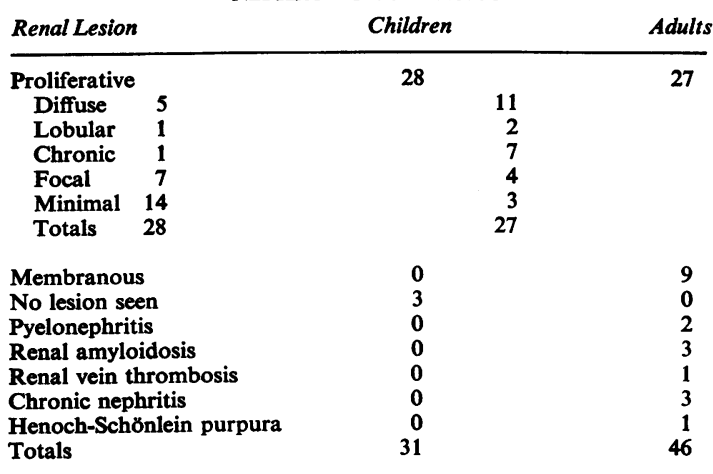

diffuse throughout the tufts and usually all the glomeruli were involved; in some glomeruli proliferation was more pronounced in one segment of a tuft. A secondary increase in basement membrane fibrils was present in many of these biopsies (Fig. 1). Occasionally, glomeruli in some biopsies showed complete sclerosis. Some proliferation and swelling of the capsular cells might be seen but crescent formation was not a feature (Fig. 2). As in other groups, hyaline droplet change was common in the proximal tubular cells; some tubular atrophy and an increase of interstitial tissue was seen in those biopsies in which there was a marked increase in basement membrane in the glomerular tufts.

Sixteen patients showed these diffuse proliferative lesions, of whom 11 were adults and five children.

Lobular The lesions in this group were essentially similar to the diffuse proliferative group but there was a distinct lobular pattern in the glomerular tuft which sometimes mimicked the lesion of a diabetic kidney (Fig. 3). The lobules contained an irregular central mass of basement membrane material with an increased number of tuft nuclei. The tubular and interstitial changes in this group were similar to those with diffuse proliferation.

Three patients showed the lobular lesion: one of these was a child.

Focal This term was applied to renal biopsies which showed abnormalities in less than $50 \%$ of the glomeruli. Frequently, the affected glomeruli showed 'local' or 'segmental' lesions (only part of the glomerulus being involved). In many of the cases the lesions, whether involving the whole glomerulus or only a part of it, were frankly proliferative. We have, however, included in this group some cases in which the glomeruli showed local or segmental areas of basement membrane thickening, adhesions between the tuft and the capsule, or more advanced sclerosis without proliferation. In one case which came to necropsy, glomerular lesions were present in only about $30 \%$ of the glomeruli; these included proliferative and sclerotic lesions which were diffuse in some glomerular tufts and local or segmental in others (Figs. 4, 5, and 6). In one case an initial renal biopsy showed no glomerular lesions but two subsequent biopsies showed focal and segmental lesions. Apart from hyaline droplet change in the proximal tubules, this group did not usually show marked changes in the tubules or interstitial tissue.

Eleven patients were placed in this category of whom seven were children.

Chronic This group included those cases with proliferative glomerular lesions which were in a more advanced stage with capsular adhesions, gross secondary membranous thickening, and glomerular sclerosis. Crescent formation was present in three cases though this change involved only some of the glomeruli. Tubular atrophy was a constant feature with a diffuse increase in interstitial tissue leading to disorganization of the kidney architecture. Arteriolar changes due to hypertension were present in four cases.

There were eight patients in this group but only one child.

Minimal change and no change An attempt was made in assessing each biopsy to separate a group in which no abnormalities could be seen in the specimen (no change); only three cases fulfilled this criterion and these were all children. The remaining 17 patients, of whom 14 were children, all showed some minor abnormality. This usually took the form of a focal or segmental lesion in an occasional glomerulus (Figs. 7 and 8), though some biopsies showed a generalized mild proliferative lesion in all glomeruli. Apart from hyaline droplet change in the proximal tubules, tubular changes were usually absent.

MEMBRANOUS GLOMERULONEPHRITIS This term was restricted to those cases whose biopsies showed a diffuse uniform thickening of the basement membrane of all glomeruli without any evidence of proliferation either in the glomerular tuft or capsule (Fig. 9). There were nine examples of this lesion and all occurred in adults. Four cases showed slight thickening of the basement membrane; in the other five it was more marked and in two of these there was considerable glomerular sclerosis. Eight cases were young adults and one was an elderly man of 70 who showed evidence of a superimposed pyelonephritis.

PYELONEPHRITIS WITH THE NEPHROTIC SYNDROME These two cases have been described elsewhere (Kibukamusoke, 1966d). Both patients were known to have a urethral stricture with urinary infection 


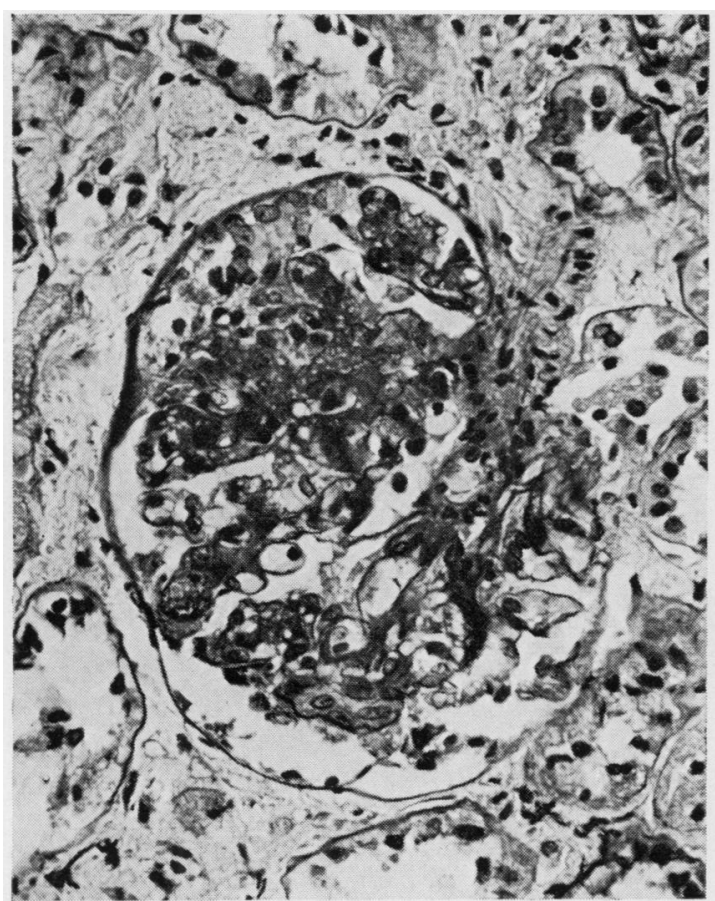

FIG. 1 .

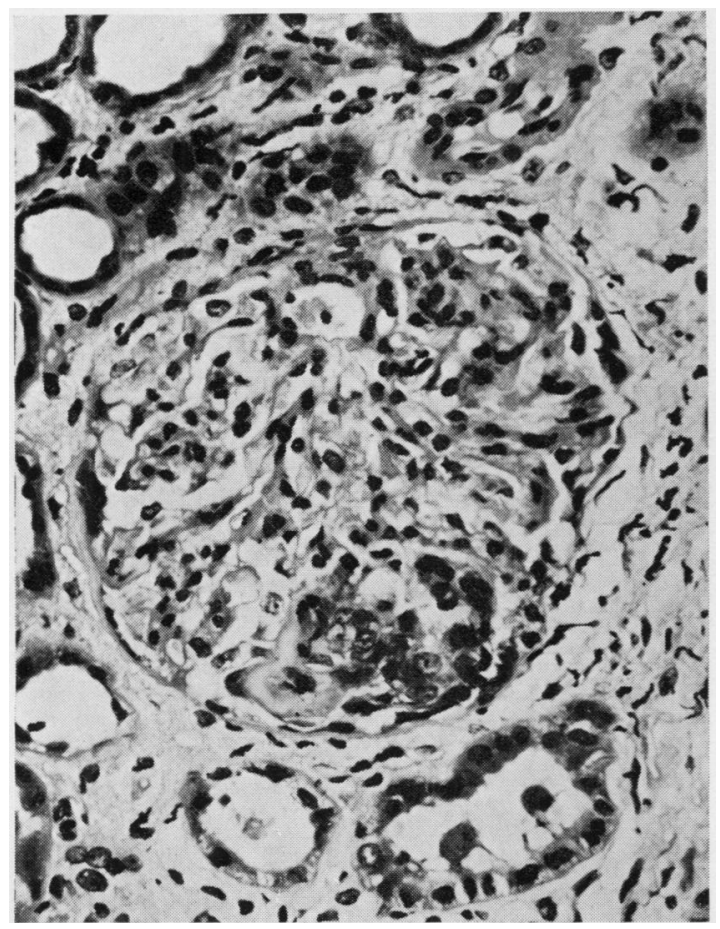

FIG. 2 .

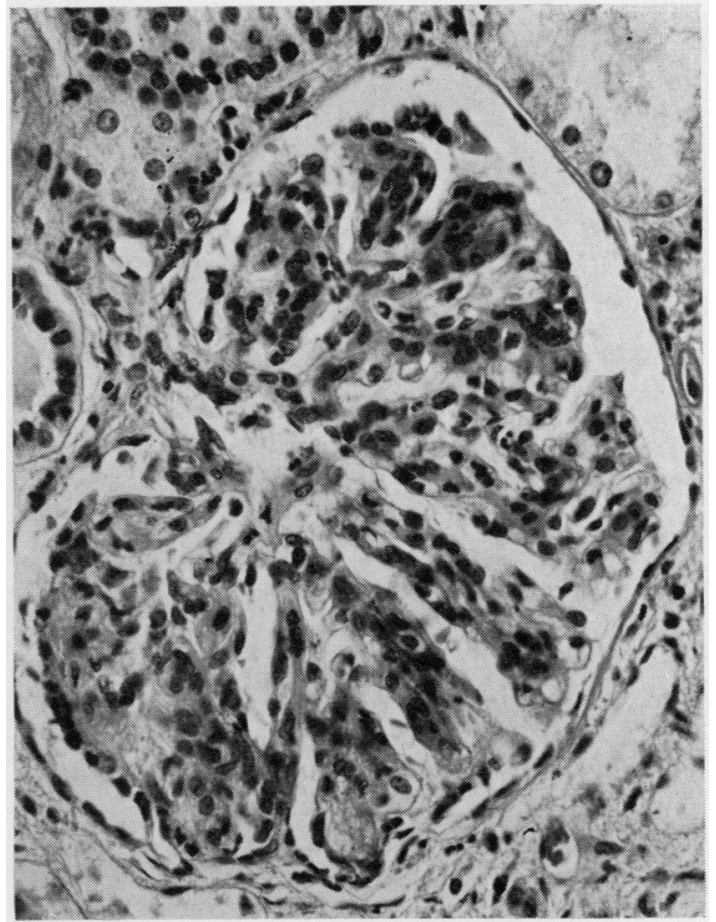

FIG. 3.

FIG. 1. Proliferative glomerulonephritis with secondary membranous change. P.A.S. $\times 260$.

FIG. 2. Proliferative glomerulonephritis with capsular proliferation. Note also atrophy of tubules and increase in interstitial tissue. Haematoxylin and eosin $\times 260$.

FIG. 3. Proliferative glomerulonephritis. Note lobulation and marked increase in size of glomerular tuft with proliferation of tuft nuclei. Haematoxylin and eosin $\times 260$. 


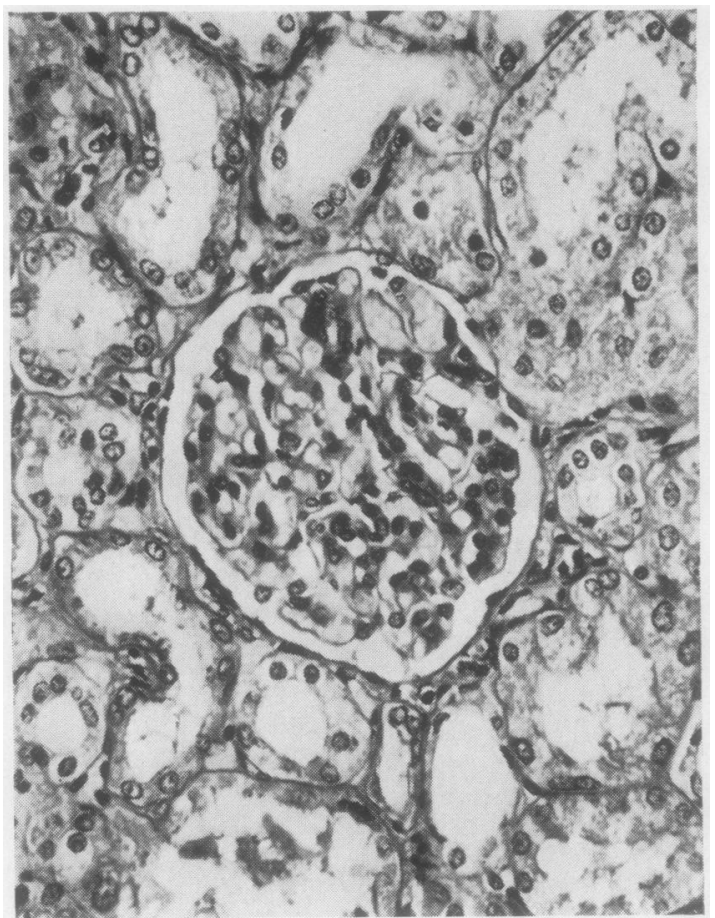

FIG. 4.

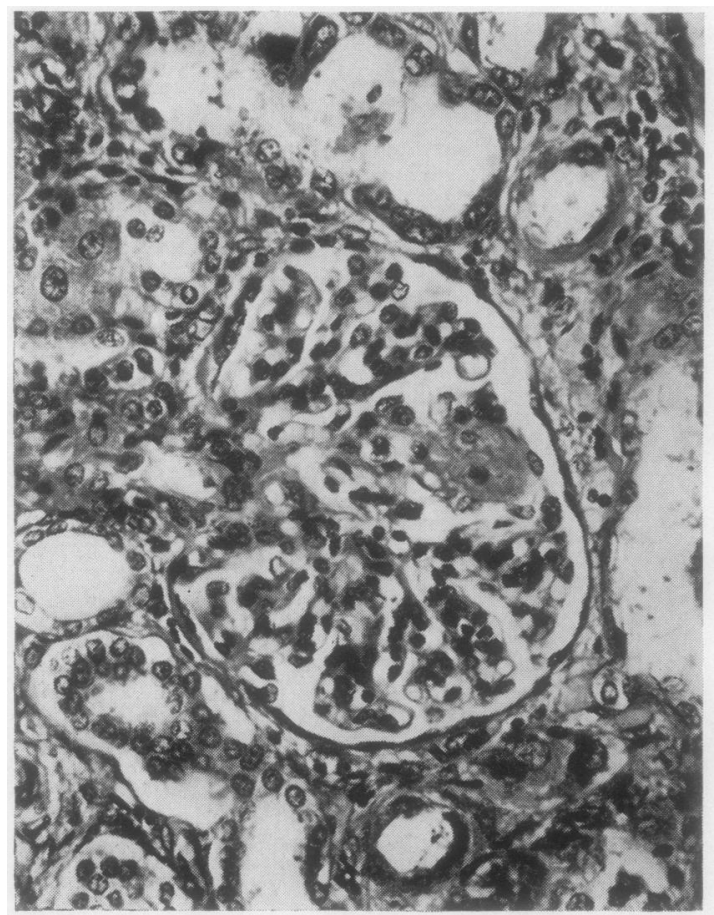

FIG. 5 .

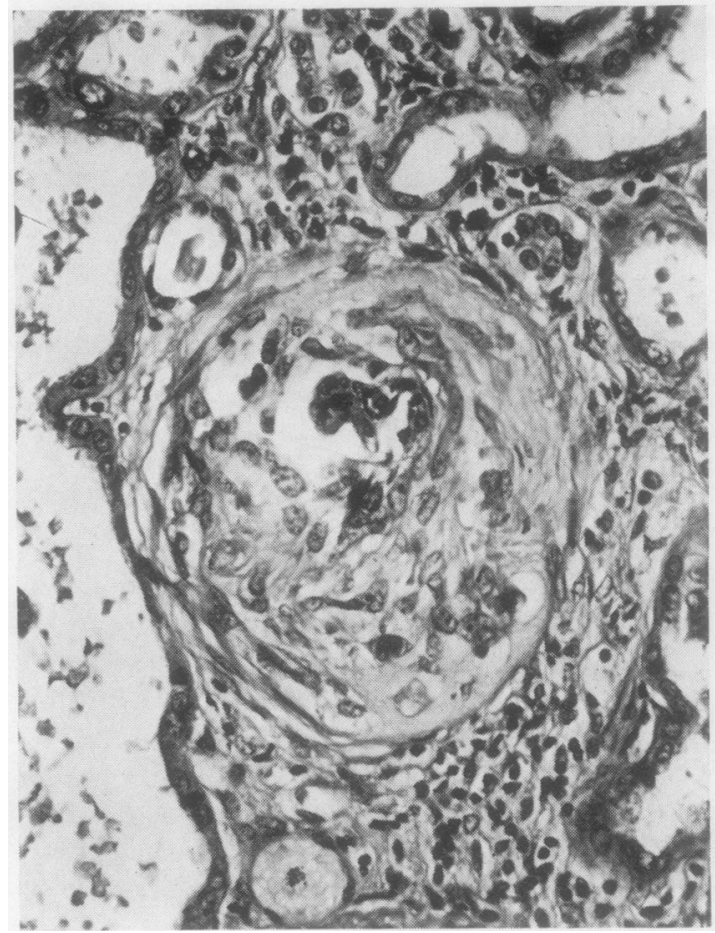

FIG. 6 .

6) in case 67. Haematoxylin and eosin $\times 260$.

FIG. 5. Focal glomerulonephritis (see also Figs. 4 and 응 $6)$ in case 67. Note local area of hyalinization with local increase in nuclei in one lobule. Haematoxylin and eosin $\times 260$.

Fig. 6. Focal glomerulonephritis (see also Figs 4 and os 5 ) in case 67. Partial sclerosis of glomerulus. Haematoxylin and eosin $\times 260$. 


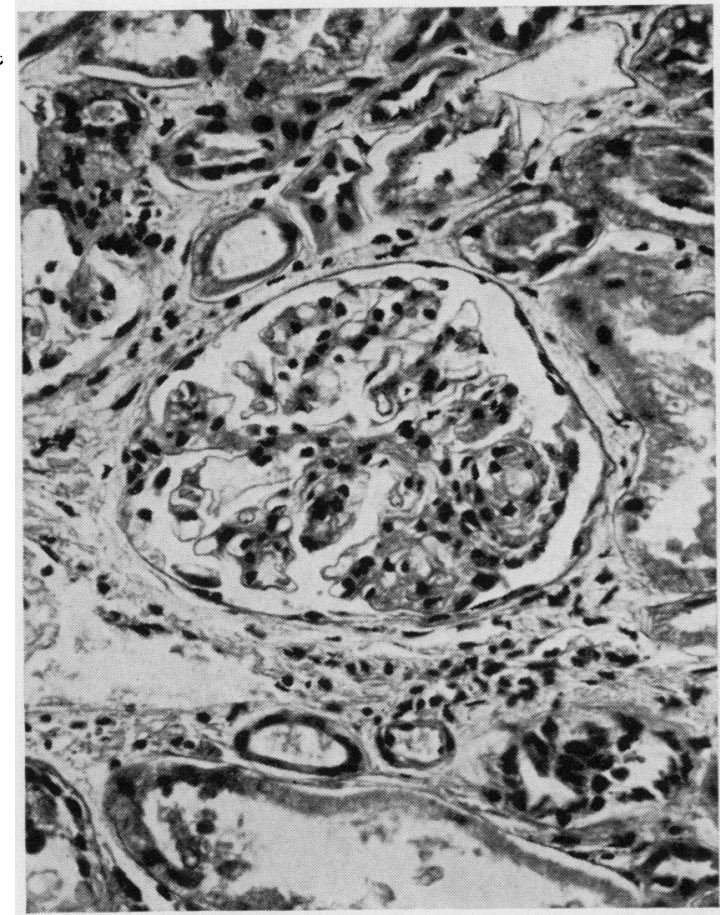

FIG. 7.

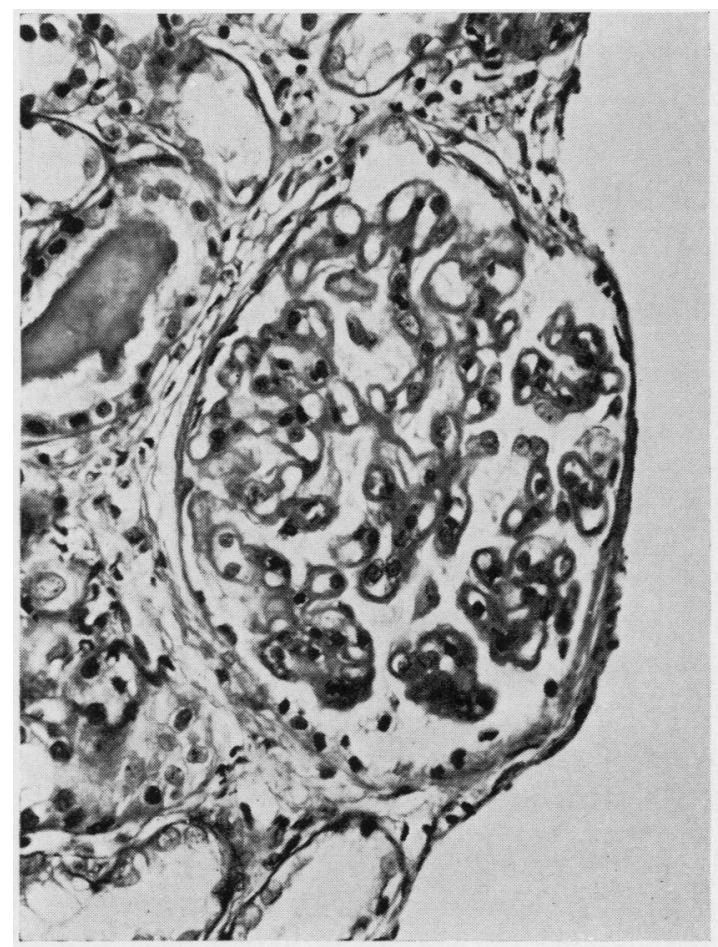

FIG. 9.

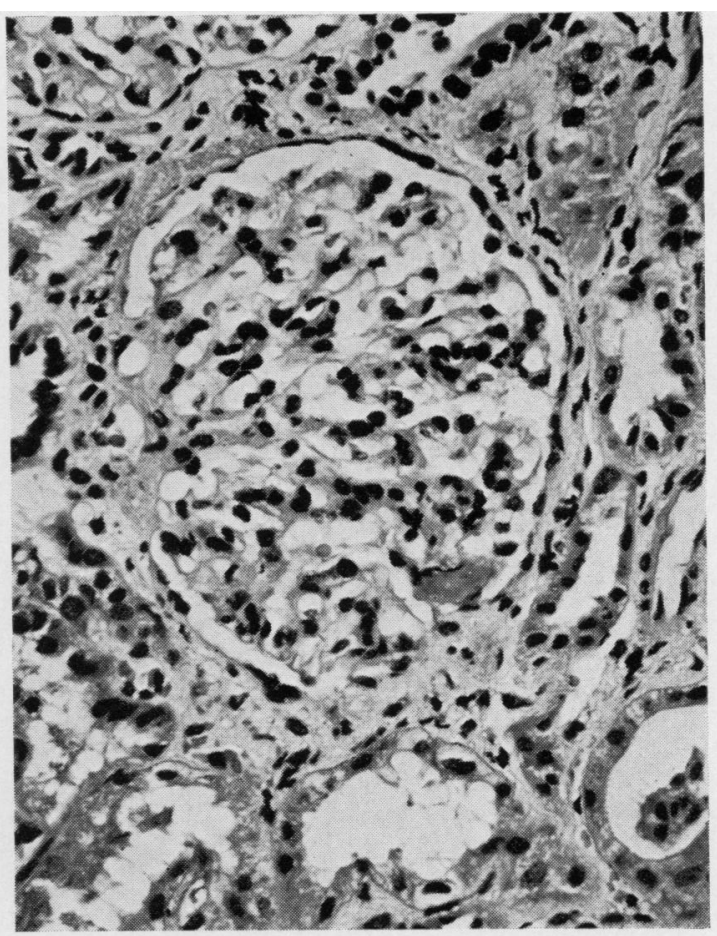

FIG. 8 .

FIG. 7. Minimal lesion. Note focal area of sclerosis in glomerulus. Most of the glomeruli in this case were quite normal. Haematoxylin and eosin $\times 260$.

FIG. 8. Minimal lesion. Slight focal proliferation with a local area of sclerosis. Haematoxylin and eosin $\times 260$.

FIG. 9. Membranous glomerulonephritis. Diffuse thickening of basement membrane with no proliferation. P.A.S. $\times 260$. 


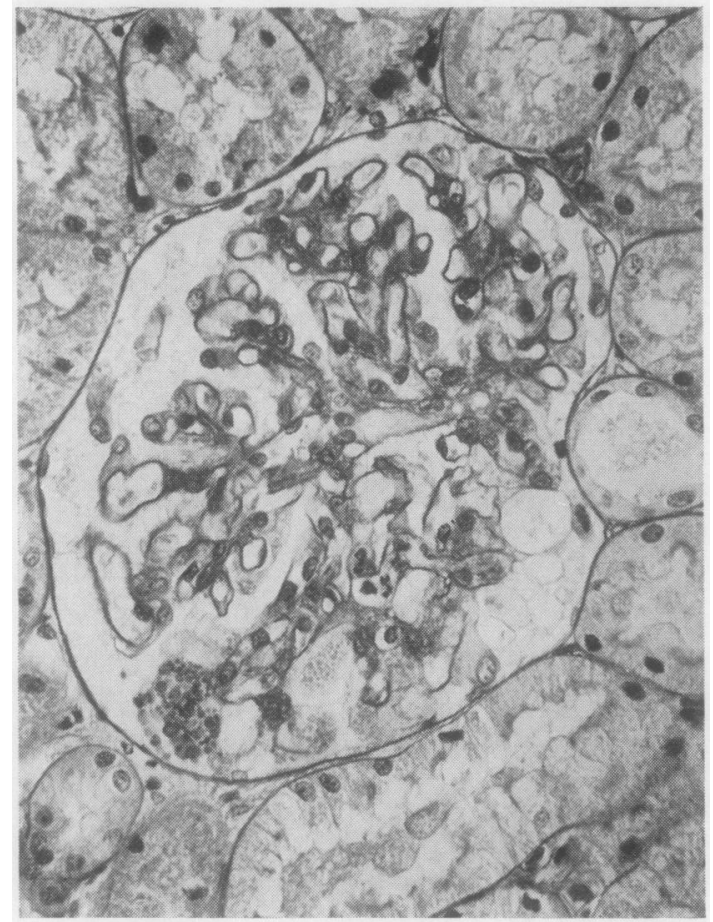

FIG. 10. Case of pyelonephritis. Glomerulus from normal area of kidney showing hyaline droplet change in epithelial cells suggesting protein leak. P.A.S. $\times 260$.

and the histological lesions of pyelonephritis at necropsy or biopsy. However, histology revealed typical proliferative lesions in the glomerular tufts of one case in areas of otherwise normal renal cortex. In the second case, hyaline droplet change was present in the epithelial cells of the glomerular tufts in the normal areas (Fig. 10); this was taken to indicate a glomerular lesion not directly due to the inflammatory process in the rest of the kidney.

CHRONIC 'NEPHRITIS' In three cases there was complete destruction of the renal architecture with glomerular fibrosis and tubular atrophy. It was not possible in this group to determine the cause of the lesions.

RENAL AMYLOIDOSIS Typical amyloid infiltration of the kidney was present in three cases. This was confirmed by the use of the polarizing effect of amyloid after staining with Congo red by methyl violet metachromasia and by thioflavine T. Two of these cases had pulmonary tuberculosis and one was primary.

RENAL VEIN THROMBOSIS This lesion was confirmed at necropsy. The kidneys showed thickening of the glomerular basement membrane only.

HENOCH-SCHÖNLEIN'S PURPURA The lesions in this case were of the proliferative type with some crescent formation. These proliferative changes remained relatively unchanged for two years.

RELATION BETWEEN MALARIAL PARASITAEMIA AND THE HISTOLOGICAL PICTURE

A summary of these results is shown in Tables II and III. Twenty-nine of the 31 cases in which Plasmodium malariae was found had one of the $\tilde{O}$ histological types of proliferative glomerulone- iv

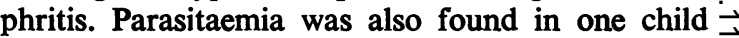
with no lesion, and one adult with pyelonephritis; this case, however, also had evidence of a pro- $\stackrel{\circ}{工}$ liferative glomerulonephritis. In striking contrast is the absence of parasitaemia in the nine patients with membranous glomerulonephritis.

The higher incidence of membranous lesions and other specific processes, such as amyloidosis in adults, may partly account for the lower rate of. parasitaemia in adults.

TABLE II QUARTAN MALARIAL PARASITAEMIA

\begin{tabular}{lcc} 
Histological Diagnosis & Positive & Total Tested \\
\hline Proliferative & 29 & 48 \\
No lesion & 1 & 2 \\
Membranous & 0 & 9 \\
Amyloidosis & 0 & 2 \\
Chronic nephritis & 0 & 3 \\
Renal vein thrombosis & 0 & 1 \\
Pyelonephritis & 1 & 2
\end{tabular}

TABLE III

\begin{tabular}{|c|c|c|c|}
\hline \multicolumn{4}{|c|}{ QUARTAN MALARIAL PARASITAEMIA } \\
\hline & $\begin{array}{l}\text { Number of } \\
\text { Cases }\end{array}$ & $\begin{array}{l}\text { Positive for } \\
\text { P. malariae (\%) }\end{array}$ & $\begin{array}{l}\text { Controls Positive } \\
\text { for P. malariae (\%) }\end{array}$ \\
\hline $\begin{array}{l}\text { Children } \\
\text { Adults }\end{array}$ & $\begin{array}{l}27 \\
38\end{array}$ & $\begin{array}{l}63 \\
40\end{array}$ & $\begin{array}{l}7 \cdot 1 \\
5.0\end{array}$ \\
\hline
\end{tabular}

\section{DISCUSSION}

Although Plasmodium malariae has been recognized for many years as a common cause of the nephrotic $\stackrel{\circ}{\circ}$ syndrome in the tropics, it is a remarkable fact that $\mathscr{D}$ few standard text-books refer to this. Kibukamusoke (1966a) has presented evidence which suggests that the nephrotic syndrome occurs with a higher fre- $\frac{\mathbb{D}}{\mathbb{D}}$ quency in tropical areas than in temperate climates $\frac{?}{\Phi}$ and he relates this to Plasmodium malariae in- $\odot$ fection. Parasites have never been demonstrated in the renal lesions and it seems reasonable to suppose 
that the glomerular changes are the result of an antigen-antibody reaction. It is possible that the parasite shares an antigen with some glomerular structure.

Gilles and Hendrickse (1963) reported proliferative and membranous lesions in a series of cases biopsied at Ibadan, Nigeria. In the cases reported here, 30 of the 31 patients in whom Plasmodium malariae was found showed one of the variants of a proliferative lesion. Recently, several biopsies from cases of the nephrotic syndrome due to Plasmodium malariae infection occurring in Lagos have been examined. These showed a similar range of glomerular lesions (Kibukamusoke, 1966e).

Pure membranous lesions were seen in nine of our cases but in none of these were malarial parasites found. The diffuse proliferative and focal forms of glomerulonephritis described in these patients with Plasmodium malariae infections have similar histological features to cases of the nephrotic syndrome occurring in temperate climates (Joekes, Heptinstall, and Porter, 1958; Heptinstall, 1960; McGovern, 1964).

Focal glomerulonephritis, as used to describe a histological picture, is not specific for the nephrotic syndrome. It may easily be missed on a renal biopsy unless all glomeruli are carefully assessed (McGovern, 1964). Several of the cases in this series were originally reported as 'no change' but on careful assessment showed involvement of an occasional glomerulus, often with a local or segmental lesion. The glomerulus has a limited repertoire of responses to an injurious agent, and it is probable that the same agent may produce a variable histological picture and conversely that different noxious agents may produce similar lesions. Further studies on the immunological and histological features of the nephrotic syndrome due to Plasmodium malariae may help to extend our knowledge of the pathogenesis of 'glomerulonephritis'.

Our thanks are due to Dr. N. E. Wilks for the parasitological studies and to Dr. John C. McAlpine for the photomicrographs.

These studies were supported by the World Health Organization and the U.S. Army Medical Research and Development Command grant No. DA-MD-49-193-636101. We should also like to thank the Chief Medical Officer, Uganda, for permission to publish.

\section{REFERENCES}

Allen, A. C. (1962). The Kidney. Churchill, London.

Clarke, J. T. (1912). J. trop. Med. Hyg., 15, 133.

Giglioli, G. (1930). Malarial Nephritis. Churchill, London.

- (1962a). Ann. trop. Med. Parasit., 56, 125.

- (1962b). Ibid., 56, 101.

Gilles, H. M., and Hendrickse, R. G. (1963). Brit. med J., $2,27$.

Heptinstall, R. H. (1960). Diseases of the Kidney. Churchill, London.

Joekes, A. M., Heptinstall, R. H., and Porter, K. A. (1958). Quart. J. Med., n.s. 27, 495.

Kark, R. M., and Muehrcke, R. C. (1954). Lancet, 1, 1047.

Kibukamusoke, J. W. (1966a). M.D. Thesis, University of E. Afr. Medical School Library. (1966b). In the press.

- (1966c). In the press.

- (1966d). E. Afr. med. J., 43, 515.

(1966e). W. Afr. med. J., 15, 213.

, and Wilks, N. E. (1965a). Lancet, 1, 301.

,$--(1965 b)$. E. Afr. med.J., 42, 203.

McFie, J. W. A., and Ingram, A. (1917). Ann. trop. Med. Parasit., $11,1$.

McGovern, V. J. (1964). Aust. Ann. Med., 13, 306.

Menon, T. B., and Annamalae, D. R. (1933). J. trop. Med. Hyg., 36, 381.

White, R. H. R. (1962). Lancet, 1, 673. 